\title{
Control centers design for ergonomics and safety
}

\author{
Leonardo Quintana, ${ }^{\mathrm{a},}$, Cesar Lizarazo ${ }^{\mathrm{b}}$, Oscar Bernal ${ }^{\mathrm{b}}$, Jorge Cordoba ${ }^{\mathrm{b}}$, Claudia Arias ${ }^{\mathrm{b}}$, Magda \\ Monroy ${ }^{\mathrm{b}}$ Carlos Cotrino ${ }^{\mathrm{c}}$, Olga Montoya ${ }^{\mathrm{c}}$. \\ ${ }^{a}$ Ergonomics Studies Center, lquin@javeriana.edu.co, Javeriana University, Calle 40 No 5- 37, Bogota \\ Colombia, ${ }^{b}$ Ergonomics Studies Center, Javeriana University ${ }^{c}$ Electronics Department, Javeriana University,
}

\begin{abstract}
This paper shows the general design conditions about ergonomics and safety for control centers in the petrochemical process industry. Some of the topics include guidelines for the optimized workstation design, control room layout, building layout, and lighting, acoustical and environmental design. Also takes into account the safety parameters in the control rooms and centers design. The conditions and parameters shown in this paper come from the standards and global advances on this topic on the most recent publications. And also the work was supplemented by field visits of our team to the control center operations in a petrochemical company, and technical literature search efforts. This guideline will be useful to increase the productivity and improve the working conditions at the control rooms.
\end{abstract}

Keywords: safety; control center; interface; architectural; ergonomics criteria, ergonomics arquitectural design, petrochemical industry

${ }^{*}$ Corresponding author. E-mail: lquin@javeriana.edu.co. 


\section{Introduction}

Automation of processes has been increasingly advance in the petrochemical industry, accelerating the pace of the technological innovations, the demand for better quality and accuracy, and the increasing complexity of processes, to require less field operators and more qualified operators at rooms and / or control centers, and therefore greater ergonomics and human factors demands.

The present study considers the workplace as a whole, including monitors and related equipment needed for the worker to make operational decisions that allow the operation of the process plants. Principles of ergonomics and safety were considered for design of control centers and for updating the current facilities. This study developed a guide that addresses the needs of today's control centers, a space with more functionality and comfort for the operators, due to their well being affect the decision making process. The operator's actions depend on the optimal workplace and, any mistake decision can have a direct impact on the integrity of people, environment and company assets. The study took into account the physical condition of the furniture and fixtures included but not limited to location, orientation, distribution, organization and space, anthropometric measures of workstations, lighting conditions, noise and temperature, safety, ventilation and conditions for the ergonomic design of the human-machine interface.

\section{Methodology}

The approach followed for the development of the guide was based on the "User-centered design" concept. Therefore users and their needs have been taking in account in all the project phases, through participatory ergonomics activities like personal interviews, focus groups, and on site surveys.

The present study is the result of a two phases process: diagnostic and a guideline development. The diagnostic phase included a questionnaire adapted from the ergonomics rating strategy Déparis and Sobane developed by Jacques Malchaire, (2004) and a structured interview with the control room operators, included the human and technical needs that were addressed.

The study used a checklist designed and adapted from: A Guide to the Ergonomics of Manufacturing (Martin Helander, 2005). This list was filled out simultaneously with the interview, by another team member. While the interview, several aspects of the operators activities were documented and reported, including a photographic record of the entire workspace.

Subsequently, the qualitative information from the interviews, the quantitative checklist and the photographic record information were confronted to analyze and diagnose any sub standard situations and activities undertaken in the current control centers.

The next step was the statistical analysis of the data using standard tools and a Fuzzy Inference System for automatic estimation of discomfort based on different entry criteria and rules.

Based on the findings of diagnostic phase, the development phase was conducted. This includes the construction of an integrated guide to ergonomic criteria and requirements for design and implementation of control rooms and control centers, taking into account current regulations and national and international standards.

The following diagram of figure 1 shows a summary of the items covered in the guide: 

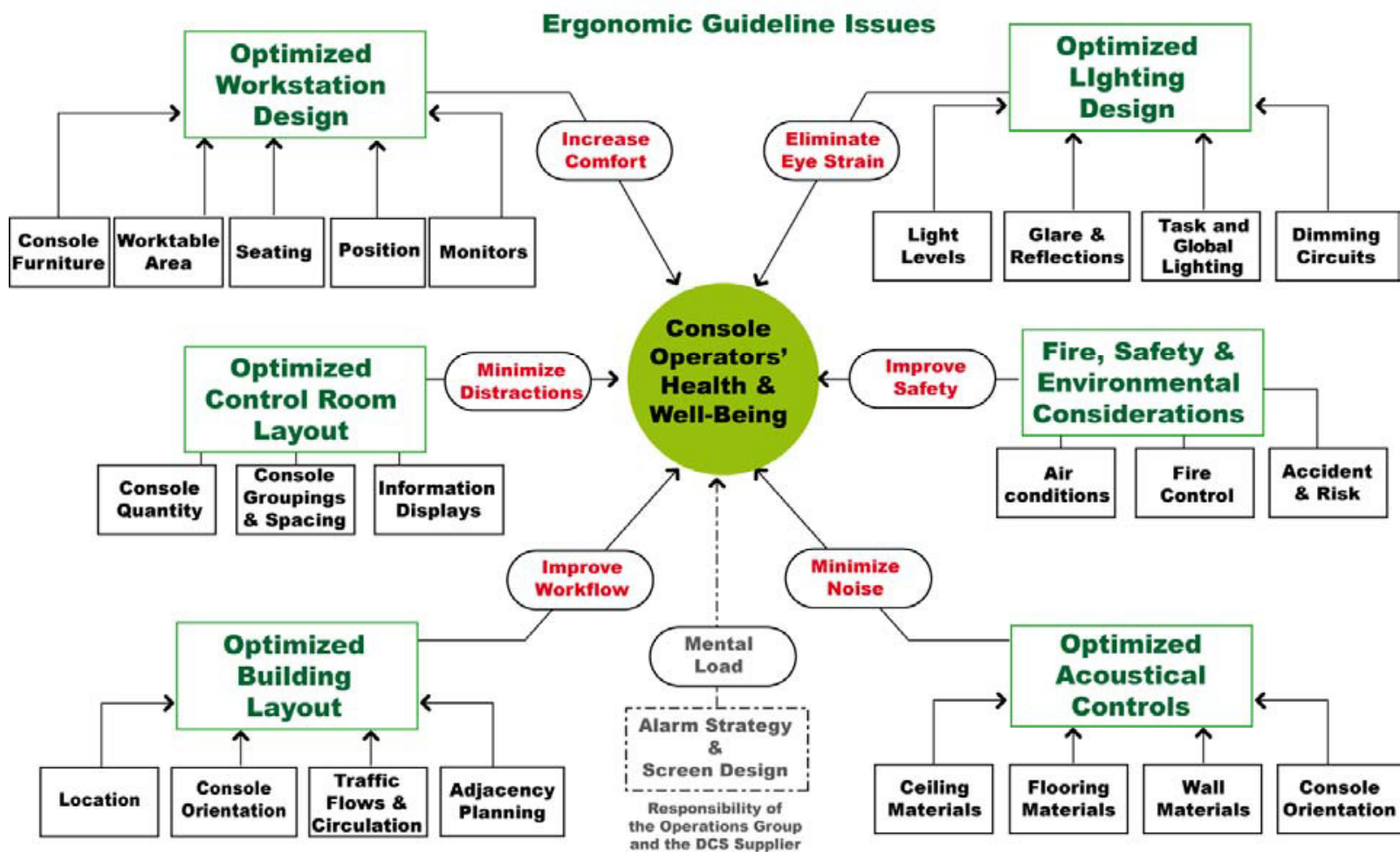

\section{Design parameters for Control Centers}

Following the methodology the ergonomic and safety considerations were:

\subsection{Considerations of location for safety.}

\subsubsection{Location of the control Center}

The control center location depends on the process that would be carried on. Accordingly, here are included some general parameters for the building location.

The location of the control center should be the first consideration to take into account when designing a safe and planned control center. The study identified the desirability of planning the location of the center on the outskirts of the process plant to provide an escape route as safe as possible. A separation of 20 to 30 meters at least between hazardous areas and the center or control room is recommended, however it should be a blast study and control the building should not be hit by a wave with a pressure higher than 1.0 PSI, a graphic representation is shown in Figure 2.

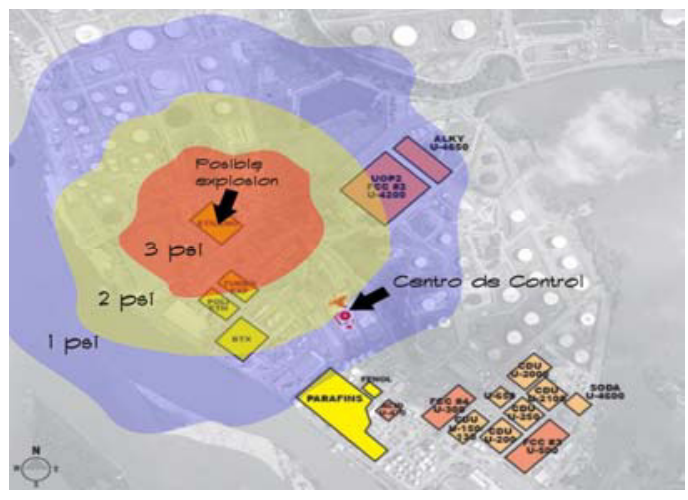

Figure 2

Structures near the center of control that are at risk of falling, should be avoided when making the planning of the control room location, and the 
roof of the building where the operators are placed on should not be supportive of machinery or heavy equipment.

The construction of the control room should take into account the existence of chemicals and toxic atmospheres. It is advisable to avoid placing the centers or control rooms adjacent to buildings containing machinery generating noise and vibration. When it is unavoidable to locate the control center in the area of influence of a possible explosion, it should be assessed and compensated for the increased risk involved in this decision with other security measures such as use of firewalls or additional safety equipment

\subsubsection{Fire Control}

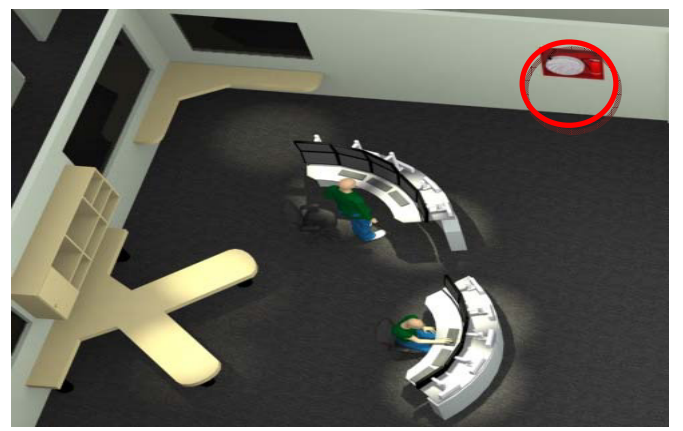

Figure 3

Despite the low rate of occurrence of fire events in the control rooms, the risks continue to increase as computers require more power and generate more heat, the uninterruptible power systems and storage batteries, generate an additional risk. As shown in Figure 3

It is for this reason that there should be a fire control room in all buildings and should not be used as storage rooms. The fire control rooms should have sufficient space to accommodate the (s) pump (s) counter-fire hoses, fire control panel, etc. and must have enough space to carry out maintenance and testing. In addition to the fire control systems referred to the control center, it must be defined how long to hold the walls of the room, which houses critical electronic equipment, as well as the time required to operate in emergency conditions and ensure routes evacuation.

\subsubsection{Access controls}

The use of access controls should be performed in restricted areas where it is necessary to register people entering and verifying whether they are authorized to enter premises. Control access should include:

- Main entrance (after the lock): Access to supervisors center operators and control engineers.

- Entrance to the control room: Access to the control room operators and supervisors.

- Engineering or technical Room: Access to control engineers and technicians.

Personal identification cards are one of the methods used for access control, thanks to technologies that can be integrated as bar codes, magnetic stripe, proximity cards and smart cards. During the study identified the desirability of using biometric systems as systems of control and accuracy for the registration of staff as it eliminates the possibility that a person made through other registration records giving your card or key.

\subsection{Conditions of orientation and spatial distribution}

\subsubsection{Console Orientation}

All operators must develop a mental map of the site, units, locations and process flow. The "cognitive map" of the operators is an important criterion in the orientation of the consoles in the control room, and the plant.

The consoles should be oriented so that the operator is facing the process to facilitate decision making and avoid errors of location. Operators should be avoided with the process control their backs. The consoles don't need to physically see the process, only to have their consoles aimed.

The operator's consoles must be oriented in the flow of the process. From left to right which is the first process, then the process or part of the process that follows the operation, and so on. 


\subsubsection{Circulation and traffic flow}

Inside of the control room, the flow of personnel should be in front of the operator's console, not behind them to avoid distractions and discomfort.

In the analysis of circulation, movement and flow of personnel, it should be taken into account the entrances, the exits of the control room and the location of consoles so that seek to "see" directly to the doors. Also it should be taken into account the considerations previously mentioned of access control to prevent flow of personnel that do not have to do with the operation. Figure 4

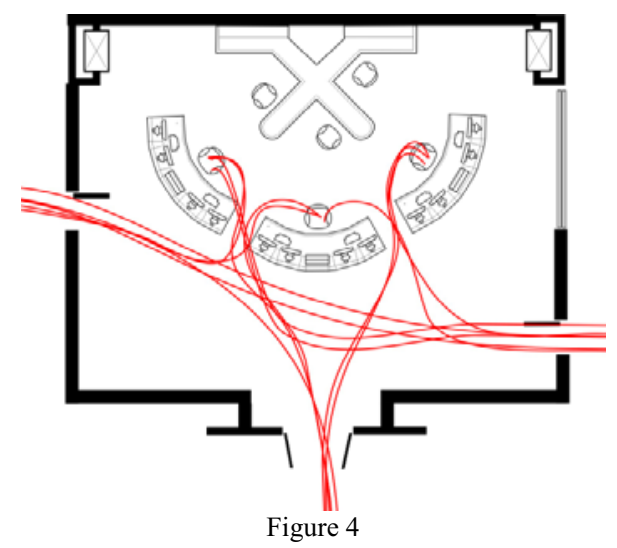

\subsubsection{Proximity planning}

By locating corridors around the control room eliminates the need for anyone other than traffic operation inside the control room, so this is recommended. Locate the restrooms services, the supervisor's room, the documentation room and the coffee room immediately next to the control room without direct access from these rooms from inside the control room reducing long stretches of travel for the operators.

The coffee room should be adjoining the control room and can be communicated through a polarized acoustic window according to the recommendations in this document, allowing observing the process, but not in the opposite direction.

The technical room, for electronic and mechanical equipment must be at one end of the building, as far as possible away from the control room. It is desirable to have at least two entrances / exits. (Main entrance and, at least 1 emergency exit). The main entrance should have lock structure.

Include storage room and / or room to the concierge in order not to have items stored in the control room. For control centers medium and large it can be placed a training station with a console-like features that can be operated by trainees. Consideration should be given office space and a conference room and separate meetings of the control room.

The area of permits and administrative activities related to the operation should not be within the control room, but must be communicated through a window in the hallway, or control room supervisor's office for processing through permits it. We recommend installing a waiting room at the permits window.

\subsubsection{Lighting Conditions}

Taking into account the different activities carried out by staff within the control room, work continuously for 24 hours and various visual abilities of the operators, the lighting design must consider the following aspects:

- Provide adequate lighting for reading documents and operating keyboards or keypads, should improve the readability of information on active and passive displays, self-illuminated equipment such as CCTV, VDT, generators and light alarm process status.

- The single fluorescent lighting is not adequate for the visual comfort of the operators.

- Reflections should be avoided, whatever its source, for example lighting, reflections by the difference in luminance over the visual field. The qualification of lighting installations can be determined using the limits specified in ISO / IEC 8995.

- Objects must be removed behind the consoles that can generate unwanted reflections as tables or shelves with glass.

- Avoiding the use of light bulbs or fluorescent lamps that create reflections in the peripheral visual field. 
- The fixtures should be located so that eliminates reflections of light bulbs or fluorescent lamps that create reflections in the peripheral visual field.

Avoid light falling directly on screen. The layout, angles and location of these shadows can prevent darkness cover part of the screen generation discomfort.

- Rooms throughout the building must be equipped with permanent emergency lighting.

- The organization of the lighting should be appropriate for the visual demands of the tasks carried out in the work environment and must consider the demands of a normal and emergency work as well as considerations of the effects of natural and artificial light.

- You must use 500 to $700 \mathrm{~lx}$ in the computer and work area, with the possibility of regulating the amount of lighting in each workplace. These levels should be reviewed to operators of 12 hour shifts sitting in front of the screens.

- When you specify lighting levels, those levels should be maintained during the life of the luminaries.

- Lighting systems must consider future changes in equipment, physical distribution, and teamwork. The options to rearrange the lights should be considered in light of this document.

- Adjust light levels to optimize the rate of brightness between the different visual fields to be addressed by the operator, including screens, adjacent areas to the edge of the screen, the keyboard, and work surfaces.

- Rates of brightness between the screens and the adjacent environment (surfaces and notebook, etc.) must not be greater than 1:3, a contrast ratio of $1: 10$ is acceptable between the screen and the areas illuminated remote, so, if it measures $70 \mathrm{~lx}$ in or around the screen, the edge areas and the keyboard should not exceed $210 \mathrm{~lx}$ and other areas in the visual field operator should not exceed $700 \mathrm{~lx}$.

- Once you have established adequate lighting levels for the consoles, then consideration should be given supplementary lighting in different areas of the control room. Whenever the selected luminaries type, does not cause any glare or reflections may be from any manufacturer.

- It was found that the combined illumination from fluorescent lamps (with parabolic lighting) and additional lights down, they are an effective solution for adding light in or around the control room. In addition, these fixtures should provide enough light for cleaning and maintenance activities, also with regulators so that the lighting level can be reduced in the normal operation of the room.

Reflection ranges of the interior surfaces must be (ISO-8995 "Lighting of indoor workplaces")

- Ceiling: 0.6 to 0.9

- Walls: 0.3 to 0.8

- Floor: 0.1 to 0.5

- The physical layout of the console determines lighting requirements, therefore, the orientation of the consoles should be considered in determining lighting needs and location of lamps on the top of the equipment.

- The adjustable task lighting should be given the conditions and different characteristics of each operator, also noting that stations have selfilluminated devices.

- The operator task lighting should not interfere with the illumination of other different workstation. Figure 5

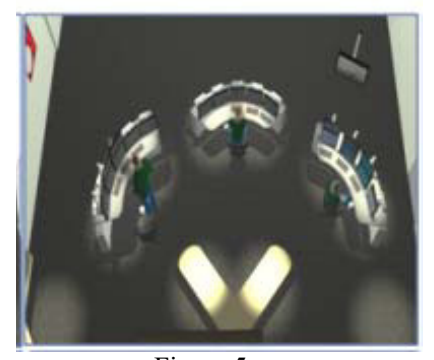

Figure 5

- Should consider the different visual demands associated with the perception of the data presented on a screen. As is the case of reading of texts and graphics analysis, screen-based information is not, for example, reading texts in drawings, watching screens on the walls that may be present in the same workplace.

- The required number of fixtures of lamps from 100 to 150 Watt should be designed to provide 25 to $200 \mathrm{~lx}$ (adjustable) to produce an appropriate coating beam in the general area of the control room; this condition does not apply to specific lighting in the office work.

- The required number of light fixtures from 100 to 150 Watt should be designed to provide 25 to 200 1x (adjustable) to produce an appropriate 
coating beam in the general area of the room, this condition does not apply to specific lighting in the workplace.

- The distribution of the luminaries of 4 to 6 uniform lighting over the console can be combined with the $2 \times 2$ fluorescent lights to achieve optimal levels of illumination.

- It should be considered the radius of curvature of the consoles to effectively place the lights and shadows to avoid uncomfortable or inadequate brightness.

- It should be considered lighting levels taking into account the need for legibility of the documents in the rear console, the night monitoring of the process and maintenance activities including cleaning.

- Where possible, lighting systems should use different light sources, both natural and artificial. The location of any window, lattice or lighting fixtures should minimize the potential for generating and discomfort glare from direct light and must take into account the conditions of ventilation and location of the control center before using any natural light sources.

- The general lighting of the room must operate with optimum quality $7 \times 24$ hours.

- In the event of emergency power failure, lighting must exist to allow staff to continue the operation or if appropriate, develop emergency procedures.

- The minimum duration of the emergency lighting should be one hour.

- In rooms where critical activities are developed, emergency lighting should be $100 \mathrm{~lx}$ at a height of $0.76 \mathrm{~m}$ above the floor.

\subsubsection{Acoustic Conditions}

The key to the success of a control room is solving the problems of acoustics, which are produced by the presence of people and equipment. One of the concerns of the operators is the noise, defined as unwanted sound. There are several ways to control noise in the air (sound generated from the speech, radio noise, alarms, etc.) In a control room, the strategies being considered to absorb noise, lower energy transmitted in the medium are:

- Sound deadening on the floor mat using refinery finishes appropriate for the harsh environment.

- Absorb sound with paneled walls and finishes
- People working inside the room should be kept separate from the noisy equipment such as air conditioning; some of these teams should be isolated in a special room with noise-absorbing materials. See figure 6 for a recommended set up.

- The average noise level inside the control room should be up to $55 \mathrm{db}$. The acceptable range for that level is 45 to $50 \mathrm{db}$.

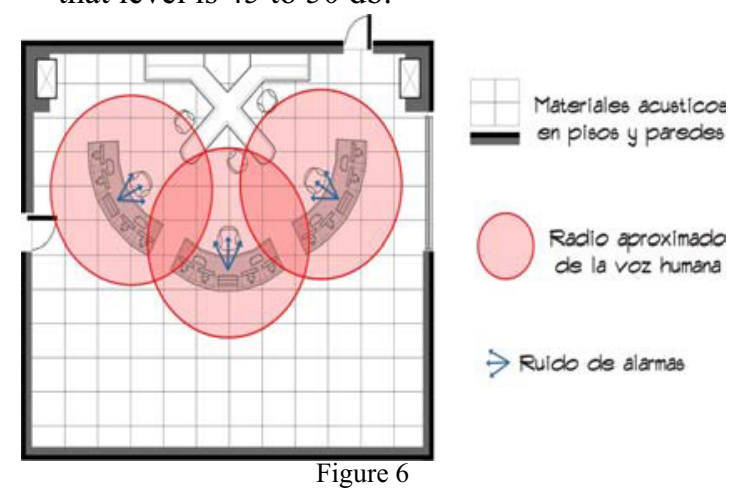

- Absorb sound in the ceiling, using noise reduction systems, placing the console to direct the sound to the vicinity using acoustic finishes and other sound reduction materials.

- Since the noise wave has a direction, It should be discussed the generation of noise both equipment and people to properly locate the workstations in order to decrease the noise discomfort. This uses radio charts with the voice and direction of the sound of alarms, Figure 6.

- Absorb sound in the ceiling, using noise reduction systems, placing the console to direct the sound to the vicinity using acoustic finishes and other sound shocking materials.

- Since the noise wave has a direction, you should discuss this generation of noise both equipment and people to properly locate the workstations in order to decrease the discomfort generated. This uses radio charts with the voice and direction of the sound of alarms, Figure 6.

- The provision of equipment set out, allows the noise generated in the operation, travel through the air directly into the walls made of materials capable of absorbing it. The ceiling and the floor will not allow sound waves propagate in such a way that disturbs other operators. 
3.2.6. Conditions for the design of control room

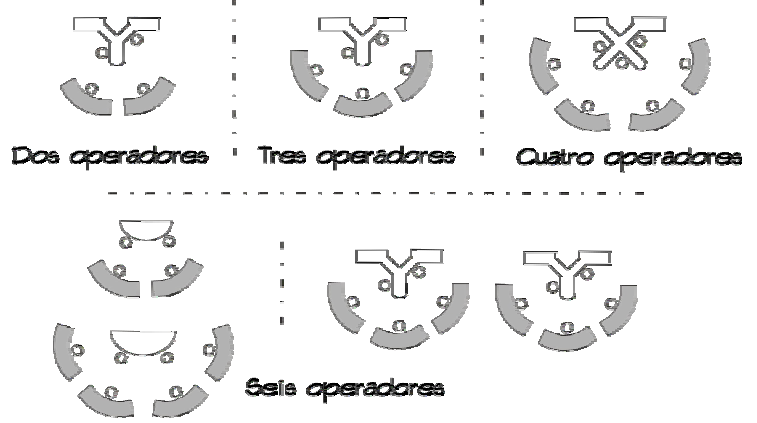

Figure 7

- There are several basic configurations of control rooms here as examples of common minimum standards needed to ensure adequate and appropriate space for workstations, as Shown in figure 7.

- The grouping of the bays should be arched to have controls and displays at the same distance.

- The outer radius of the arc location of the consoles is defined according to the same settings. When you have 2 consoles arc radius must be at least $440 \mathrm{~cm}$, for 3 consoles minimum radius of $480 \mathrm{~cm}$ and 4 radio consoles at least $600 \mathrm{~cm}$. In the case of 6 operators, referred to two alignments that combine previously described configurations, where you can check the corresponding arc radius for the location of the consoles.

- The minimum distance between consoles is 100 $\mathrm{cm}$.

- The minimum distance between consoles and the back wall is $160 \mathrm{~cm}$.

- The minimum distance between consoles and the side walls is $180 \mathrm{~cm}$.

- Cabinet is recommended console 4 or 5 bays 1 operator, Figure 8.

- The furniture should be designed for functional work environment. The design must ensure sufficient rest so that the operator feels comfortable in your workstation.

- The work surface should be adjustable in height and adjustable to users' anthropometric dimensions of the spaces, but above all adjustable to allow normal operation both standing and sitting. Adapted to the workers in Colombia

- The minimum distance between consoles is 100 $\mathrm{cm}$.
- The minimum distance between consoles and the back wall is $160 \mathrm{~cm}$.

- The minimum distance between consoles and the side walls is $180 \mathrm{~cm}$.

- A cabinet is recommended for a console of 4 or 5 bays and 1 operator, Figure 8 .

- The furniture should be designed for functional work environment. The design must ensure sufficient rest so that the operator feels comfortable in your workstation

- The work surface should be adjustable in height and adjustable to users' anthropometric dimensions of the spaces, but above all adjustable to allow normal operation both standing and sitting

- Sliding doors are recommended in the lower pane of the console, which ensure easy, comfortable, open cable trays that allow screens to run without interruption.

- The furniture should allow the assembly of flat screens to hide including accessories and cables.

- It is recommended to use flexible modular structures, or standard modules, that allow be adding or relocating as necessary.

- The furniture should be kept clean, preferably laminated material for easy cleanup.

- The cabinet of the console should offer the possibility of holding at least 6 screens, with expansion capability up to 10 screens including CCTV monitor each location of the console.

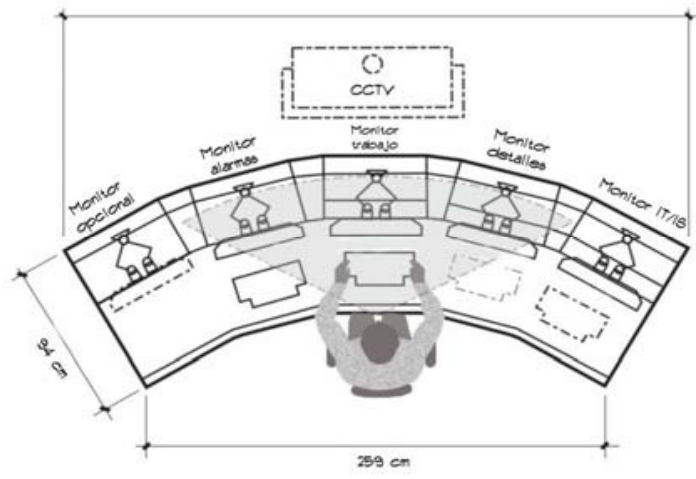

Figure 8

- The function of a seat well designed for users with visual display of data is to provide a stable and comfortable, allowing movement and tasks. It is recommended for workstations that require standing and sitting and using combinations adjustable to suit the end user. The concept of adaptation is related to key design parameters such as: 
- Adjustment the seat lumbar area.

- Adjustable arm rests.

- Support for lower back.

- The chair should prevent the spine compression, the highest seat of adapting the user will take the following parameters, for the workers in Colombia:

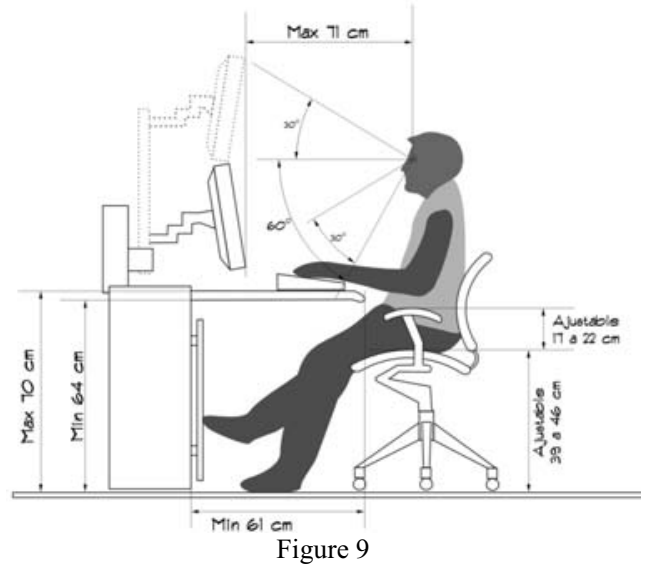

- The considerations presented above for the safe and ergonomic design of control centers, are visibly appreciated renders the following prototype, as shown in figure 10:

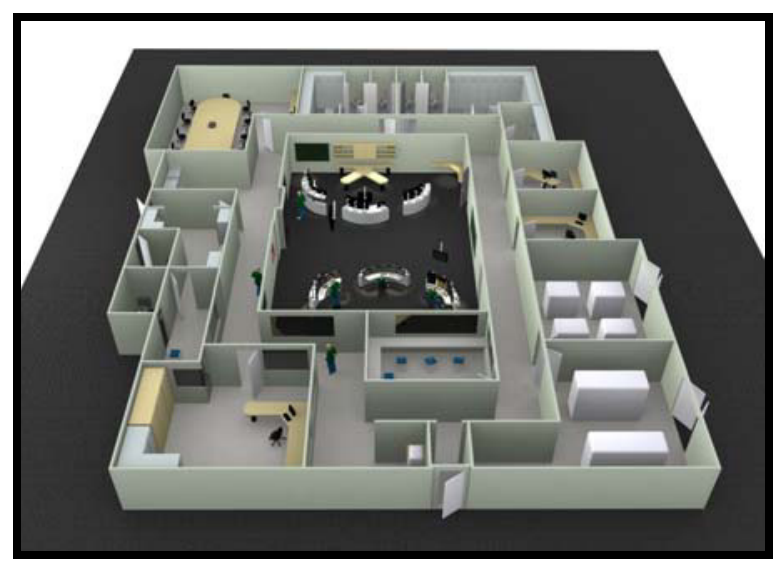

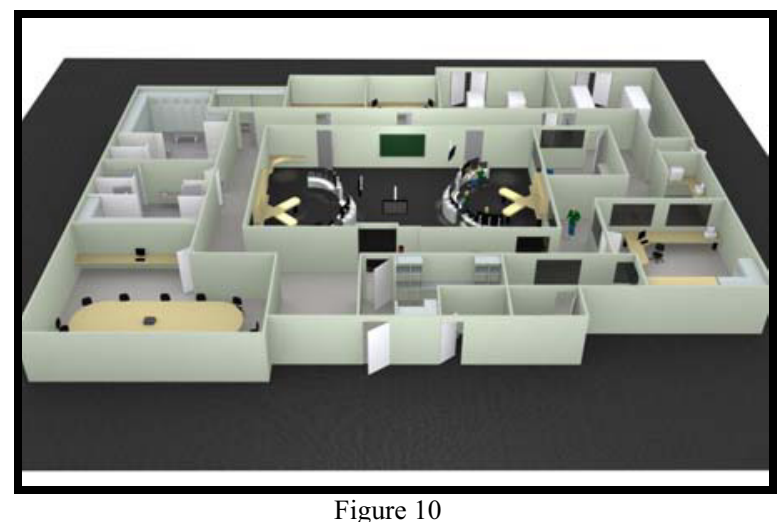

\section{Conclusions}

This study reflects as main result the "Ergonomic Aspects Guide HSE for the Design of Control Centers" which presents graphically and concrete recommendations and conditions in terms of:

- Location and safety

- Air and ventilation

- Guidance, distribution and spaces

- Lighting

- Acoustics

- Design of control room

- Furniture Workstation

- Ergonomic man-machine interface

Criteria were proposed ergonomic and safety requirements related to ergonomic architectural design elements, work stations, physical environment and distribution of elements of active and passive safety, applicable to any control room is built in the future.

Were defined minimum, desirable and ideal in terms of position or changes in posture and movement in the control room, that have been studied and that these serve to be replicated to other projects of new control rooms.

This study proposed a new contribution in literature with an ergonomic guide specializing in the design needed to make appropriate implementations in areas and work stations (including furniture) in control rooms to be built in the future, in operations of transport, production, refinery and industrial processes, seeking to obtain ergonomic standards and safety requirements for 
the design, distribution and adequacy of control rooms that tend to work efficiently, comfortably and with the improved security.

\section{Acknowledgements}

This study was possible with the collaboration of Mr. Douglas M. Spranger, president of the company Control Room Design, LLC.

\section{References}

ACGIH: American Conference of Governmental Industrial Hygienists. Threshold Limit Values.

Concentrations of hazardous compounds in the air. USA. 2010.

ANSI / ASHRAE 62.1., Ventilation for Acceptable Indoor Air Quality. USA. 2007.

Borg G., Physical Performance and Perceived Exertion. Lund, Sweden, Gleerup, 1962.
Borg, G., Borg's Perceived Exertion and Pain Scales. Human Kinetics Publishers, Champaign, Illinois, USA. 1998.

Ivergard T., Hunt B., Hand Book of control room design and ergonomics. 2009.

ISO 11064-1 Ergonomics Design of control centers. Parts 1 to 7. ISO 2000, Switzerland

Malchaire, J.B., Participative management strategy for occupational health, safety and wellbeing risks, G Ital Med Lav. Erg, 2006. 58

Regulations from: AA 00025 STD, ACGIH, ANSI C2, ANSI B 16.5, ANSI 31.3, API RP 14C, API RP-500, API RP 550, API RP 551, ASHRAE Journal NA-04-7-2, ASHRAE; EEMUA Guideline for the evaluation of light and brightness. 